Jurnal Mandala Pharmacon Indonesia, Vol 5.No.1 Juni 2019

Avaiable online at www.jurnal-pharmaconmw.com/jmpi

p-ISSN : 2442-6032

$e$-ISSN : 2598-9979

\title{
Uji Stabilitas Fisik Ekstrak Etanol Daun Jambu Mete (Anacardium occidentale L. ) Dalam Formulasi Sediaan Emulgel AntiInflamasi
}

Nur Hatidjah Awaliyah Halid, Ahmad Saleh

Program Studi Farmasi, Stikes Mandala Waluya Kendari

\begin{abstract}
ABSTRAK
Jambu mete (Anacardium occidentale L.) merupakan tanaman yang tumbuh subur di Sulawesi tenggara. Secara tradisional daun jambu mete digunakan sebagai antiinflamasi. Daun jambu mete mengandung berbagai senyawa aktif seperti flavonoid, asam anakardik, beta-sitosterol, cardol, asam linoleat, asam salisilat serta tannin. Jenis penelitian yang digunakan adalah penelitian eksperimental. Tujuan penelitian ini untuk mengetahui dan mencanangkan formula ekstrak etanol daun daun jambu mete dalam bentuk sediaan emulgel, serta mengevaluasi stabilitas sediaan emulgel tersebut secara fisik. Formulasi emulgel ekstrak etanol daun daun jambu mete menggunakan basis gel yaitu karbomer. Formulasi dilakukan dalam 3 konsentrasi ekstrak yaitu 10\%, $12 \%$, dan $15 \%$ dengan variasi basis gel $0,5 \%, 10 \%$, dan $1,5 \%$. Uji karakteristik sediaan emulgel meliputi pemeriksaan fisik yaitu pemeriksaan warna, homogenitas, konsistensi, $\mathrm{pH}$, penentuan
\end{abstract}

viskositas, uji daya sebar. Hasil penelitian ini menunjukkan bahwa ekstrak daun jambu mete dapat diformulasi menjadi emulgel dengan karakteristik yang baik. Semua konsentrasi basis gel dapat menghasilkan emulgel dengan karakteristik yang baik. Formula I, VI, VII dan IX merupakan karakteristik yang paling baik untuk sediaan emulgel ekstrak daun jambu mete (Anacardium occidentale L.).

Kata Kunci : Emulgel, Ekstrak Daun Jambu Mete, Antiinflamasi

Penulis korespondensi :

Nur Hatidjah Awaliyah Halid

Program Studi S1 Farmasi,STIKES Bhakti Husada

Mulia

E-mail : nunuawaliyah3o@gmail.com
PENDAHULUAN

Secara tradisional jambu mete (Anacardium occidentale L.) digunakan sebagai pengobatan ulkus, diabetes dan inflamasi (Periyanayagam et al., 2013). Sedangkan, daunnya dimanfaatkan sebagai antiinflamasi (Patil et al., 2003), hipoglikemik (esimone et al., 2001), antihipertensif, antidiare, antipiretik dan anti-inflamasi (Mota et al., 1985) serta vasorelaksan (Runnie et al., 2004). Studi preklinik yang dilakukan oleh Gowthamarajan et al. pada tahun 2011 juga pernah menyebutkan bahwa getah pohon jambu mete dapat digunakan sebagai agen pengikat dalam formulasi tablet parasetamol. Daun jambu mete ( $A$. occidentale L.) mengandung berbagai senyawa aktif seperti flavonoid, asam anakardik, beta-sitosterol, cardol, asam linoleat,asam salisilat serta tannin.

Ekstrak etanol daun jambu mete pada fraksi petroleum eter, etil asetat, butanol dan butanon memiliki signifikan sebagai antiinflamasi terhadap tikus putih dengan dosis $300 \mathrm{mg} / \mathrm{kg}$ bb dimana menggunakan kontrol positif sodium diklofenak dosis $100 \mathrm{mg} / \mathrm{kg}$ bb (Patil et al.,2003). Pada tahun 2000, Pawar et al., 
juga pernah menguji aktivitas antiinflamasi ekstrak daun jambu mete pada tikus albino. Dari hasil penelitian tersebut didapatkan bahwa fraksi aseton dari ekstrak etanol daun jambu mete memiliki efek antiinflamasi sebesar 61,90\%. Di Afrika, mandi dengan ramuan daun jambu mete biasanya dilakukan untuk menyembuhkan malaria (Taylor, 2005; Odugbemi dan Akinsulire, 2006). Pengobatan herbal mengklaim bahwa daun jambu mete digunakan untuk mengobati kondisi peradangan, nyeri mengobati sakit gigi, menyembuhkan luka, mengobati rematik dan disentri di bandingkan dengan penggunaan obat lain (Odugbemi dan Akinsulire, 2006).

Senyawa aktif dalam ekstrak daun jambu mete yang diduga memiliki efek antipiretik ialah flavonoid dan asam anakardik yang merupakan derivat asam salisilat (Duke, 1992). TanamanAnacardium occidentalis, menurut database yang diberikan oleh Duke (2005), mengandung metabolit sekunder, serta antioksidan yang memiliki sifat antipiretik dan antiinflamasi. Hal tersebut dikuatkan dengan penelitian yang dilakukan Onasanwo et al (2012) yang menyatakan bahwa Ekstrak etanol daun Anacardium occidentalis menyebabkan penghambatan edema karaginan yang signifikan pada tikus $(\mathrm{P}<0,05)$ dengan dosis tertentu. Temuan ini menunjukkan bahwa ekstrak daun Anacardium occidentalis adalah agen antipiretik dan antiinflamasi yang sangat ampuh. Analisis fitokimia menunjukkan bahwa ekstrak daun mengandung alkaloid, tanin, saponin dan kardenolida. Atas dasar kemampuan tersebut, penelitian ini dilakukan untuk mencanangkan formulasi ekstrak etanol daun Anacardium occidentalis dalam bentuk sediaan emulgel, serta mengevaluasi stabilitas sediaan emulgel tersebut secara fisik

\section{METODE PENELITIAN}

\section{Alat}

Spektrofotometer UV-Vis (Shimadzu, Jepang), pipet mikro (Eppendorf), homogenizer (Omni-Multimix Inc.), viskometer (Brookfield), $\mathrm{pH}$ meter 510 (Eutech Instrument), mikroskop optik (Nikon model Eclipse E200), oven (Memmert), rotary evaporator (Buchi), termometer, kamera digital (Samsung), timbangan analitik 210-LC (Adam), sentrifugator (Kubota 5100), pemanas elektrik (IKA), penangas air (Memmert) dan alat-alat gelas.

\section{Bahan}

a). Simplisia

Daun jambu mete (Anacardium occidentale L.) diperoleh dari Desa Wadonggo, Kabupaten Konawe Selatan, Sulawesi Tenggara. Daun jambu mete dipetik pada pagi hari lalu dicuci, dikeringkan dan diserbukkan.

b). Bahan Kimia dan Lain-Lain

Etanol 96\% (Brataco), n-butanol (Merck), Karbopol-940 (Lubrizol), minyak zaitun (Valdoro), Tween 60 (Merck), Span 20 (Tokyo Chemical Industry), propilen glikol (Dow Chemical Co.), mentol, BHT (SPPChemical), kalium dihidrogen posfat (Merck), natrium hidroksida (Merck) dan air suling (Brataco, Indonesia).

\section{Prosedur Penelitian}

\section{a). Ekstraksi Daun Jambu Mete}

Sampel berupa daun Jambu Mete (Anacardium occidentale) yang diambil di Desa Wadonggo Kabupaten Konawe Selatan, Sulawesi Tenggara yang telah diserbukkan, ditimbang $\pm 1 \mathrm{~kg}$ kemudian dimasukkan ke dalam bejana maserasi $5 \mathrm{~L}$. Ke dalam wadah ditambahkan etanol 
sebanyak 2 L, pelarut dimasukkan sedikit demi sedikit sampai sampel terbasahi semua. Kemudian sampel didiamkan selama 5 x 24 jam sambil sesekali diaduk dan terlindung dari paparan sinar matahari langsung. Kemudian sampel disaring menggunakan penyaring Buchner dan residu dicuci kembali dengan etanol sebanyak 2-3 kali. Filtrat diuapkan untuk menghilangkan pelarut menggunakan rotary vacuum evaporator, penangas air, dan oven vakum hingga diperoleh ekstrak kental.

b). Pembuatan Sediaan Emulgel Ekstrak Daun Jambu Mete

Pada penelitian ini dibuat tiga formulasi dengan perbandingan konsentrasi ekstrak Daun Jambu Meteyang berbeda, satu blangko negatif yang tidak mengandung zat aktif dan satu blangko positif yang mengandung Natrium Diklofenak.

Tabel 1. Komposisi bahan dalam sediaan gel dan emulgel

\begin{tabular}{|l|c|c|c|c|c|}
\hline \multirow{2}{*}{ Nama Bahan } & \multicolumn{5}{c|}{ Jumlah Bahan (\%) } \\
\cline { 2 - 6 } & F1 & F2 & F3 & Bo & B1 \\
\hline Ekstrak Etanol Daun Jambu Mete & 10 & 12 & 15 & - & - \\
\hline Natrium Diklofenak & - & - & - & - & $25 \mathrm{mg}$ \\
\hline Carbopol 940 & 2,00 & 2,00 & 2,00 & 2,00 & 2,00 \\
\hline Minyak zaitun & 5,00 & 5,00 & 5,00 & 5,00 & 5,00 \\
\hline Tween 60 & 3,60 & 3,60 & 3,60 & 3,60 & 3,60 \\
\hline Span 20 & 1,40 & 1,40 & 1,40 & 1,40 & 1,40 \\
\hline Propilen glikol & 5,00 & 5,00 & 5,00 & 5,00 & 5,00 \\
\hline Mentol & 1,00 & 1,00 & 1,00 & 1,00 & 1,00 \\
\hline Butilhidroksitoluen (BHT) & 0,03 & 0,03 & 0,03 & 0,03 & 0,03 \\
\hline NaOH & 0,60 & 0,60 & 0,60 & 0,60 & 0,60 \\
\hline Etanol 96\% & 3,00 & 3,00 & 3,00 & 3,00 & 3,00 \\
\hline Air suling & Hingga 100 & Hingga 100 & Hingga 100 & Hingga 100 & Hingga 100 \\
\hline
\end{tabular}

Keterangan: F1 = Formula 1, F2 = Formula 2, F3 = Formula 3, Bo = Blangko negatif, B1 = Blangko positif.

\section{c). Pembuatan Sediaan Emulgel (Mohamed, 2004)}

Pembuatan emulgel ekstrak etanol daun jambu mete, dimulai dengan menyiapkan alat dan bahan kemudian masing-masing bahan ditimbang sesuai dengan perhitungan yang tertera dalam rancangan formula. Fase minyak terdiri dari emulsi yang dibuat dengan melarutkan span 20, ekstrak etanol daun jambu mete dan BHT dalam minyak zaitun. Fase air terdiri dari tween 60 yang dilarutkan dalam air suling. Fase minyak dan fase air dipanaskan pada suhu $70-75^{\circ} \mathrm{C}$. Mentol dilarutkan di dalam etanol $96 \%$ kemudian dicampurkan ke dalam propilen glikol. Setelah masing-masing fase mencapai suhu $\pm 70-75^{\circ} \mathrm{C}$. Fase minyak ditambahkan ke dalam fase air yang dilanjutkan dengan penambahan campuran mentol-etanolpropilen glikol. Campuran diaduk dengan homogenizer 2500 rpm hingga suhu turun mencapai temperatur kamar dan terbentuk emulsi.

Karbomer sebagai Basis gel dibuat dengan cara didispersikan dengan menggunakan air suling sebanyak 30\% dari total massa emulgel sambil diaduk. $\mathrm{NaOH}$ dilarutkan dalam air suling sebanyak $7,4 \%$ dari massa total emulgel kemudian ditambahkan ke dalam basis gel karbomer dengan homogenizer 1500 rpm hingga terbentuk basis gel kental.

Emulgel dibuat dengan mencampurkan emulsi ke dalam basis gel sedikit demi sedikit dengan homogenizer 3000 rpm selama 30 menit. Perbandingan antara emulsi dan basis gel adalah 6:4. 
d). Evaluasi Sediaan (Singla, et al., 2012)

1) Organoleptis

Pengamatan organoleptis meliputi pengamatan warna, bau, dan homogenitas.

2) Homogenitas

Uji homogenitas dilakukan dengan cara mengoleskan sediaan di atas kaca objek dan diamati di bawah mikroskop.

3) Pengukuran $\mathrm{pH}$

Pengukuran $\mathrm{pH}$ dilakukan menggunakan $\mathrm{pH}$ meter dengan elektroda dicelupkan ke dalam sediaan dan dicatat nilai $\mathrm{pH}$ yang tertera pada layar. Pengukuran dilakukan pada suhu ruang.

e). Uji Stabilitas Fisik Sediaan (Djajadisastra, 2004)

1) Uji stabilitas pada suhu tinggi

Stabilitas sediaan meliputi bau, warna, dan $\mathrm{pH}$ dievaluasi pada suhu $40^{\circ} \pm 2^{\circ} \mathrm{C}$ selama 8 minggu dengan pengamatan setiap 2 minggu sekali.

2) Uji stabilitas pada suhu kamar

Stabilitas sediaan meliputi bau, warna, dan $\mathrm{pH}$ dievaluasi pada suhu $28^{\circ} \pm 2^{\circ} \mathrm{C}$ selama 8 minggu dan dengan pengamatan setiap 2 minggu sekali.

3) Uji stabilitas pada suhu rendah

Stabilitas sediaan meliputi bau, warna, dan $\mathrm{pH}$ dievaluasi pada suhu $4^{\circ} \pm 2^{\circ} \mathrm{C}$ selama 8 minggu dengan pengamatan setiap 2 minggu sekali.

4) Cycling test

Sediaan disimpan pada suhu $4^{\circ} \mathrm{C}$ selama 24 jam lalu dikeluarkan dan ditempatkan pada suhu $40^{\circ} \mathrm{C}$ selama 24 jam. Perlakuan ini adalah satu siklus. Percobaan diulang sebanyak 6 siklus. Kondisi fisik sediaan dibandingkan selama percobaan dengan sediaan sebelumnya, apakah terjadi sineresis atau kristalisasi.
5) Uji mekanik (Sentrifugasi)

Sampel disentrifugasi dengan kecepatan putaran $3800 \mathrm{rpm}$ pada radius sentrifugasi selama 5 jam karena hasilnya ekivalen dengan efek gravitasi selama 1 tahun. Setelah disentrifugasi, diamati apakah terjadi pemisahan antara fase minyak dengan fase air.

\section{HASIL DAN PEMBAHASAN \\ Determinasi Tanaman}

Determinasi tanaman jambu mete dilakukan dengan membandingkan morfologi sesuai dengan pustaka yaitu "Flora of Java" oleh Backer dan Van Den Brink (1965). Determinasi tanaman menunjukkan bahwa tanaman yang diidentifikasi adalah Anacardium occidentale $L$.

\section{Ekstraksi Daun Jambu Mete}

Penelitian ini diawali dengan penelitian pendahuluan pembuatan ekstrak etanol daun jambu mete (Anacardium occidentale). Daunjambu mete dipetik, dicuci kemudian dikeringkan berdasarkan standarisasinya. Sampel daun jambu mete kering kemudian diserbukkan sebagai simplisia. Simplisia daun jambu mete diekstraksi dengan metode maserasi menggunakan cairan penyari etanol 96. Etanol 96\% digunakan karena merupakan larutan penyari universal, yaitu dapat menyari hampir semua senyawa kimia yang terkandung dalam tanaman baik polar maupun nonpolar.

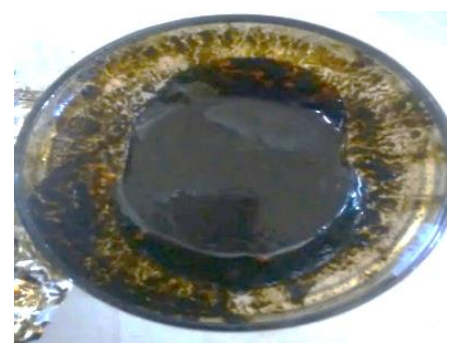

Gambar 3. Penampilan Fisik Ekstrak Kental Etanol Daun Jambu Mete (Anacardium occidentale) 
Ekstrak cair yang didapat diuapkan menggunakan rotary vacuum evaporator hingga didapat ekstrak Etanol kental. Penguapan dilakukan dengan suhu tidak lebih dari 55ㄷ (Gaedck, Steinhoff, dan Blasius, 2000). Penguapan yang terus menerus dan berulang bertujuan untuk menghilangkan sisa pelarut ekstraksi dari jambu mete. Ekstrak Hijau gelap seperti terlihat pada Gambar 3 Ekstrak yang diperoleh kemudian ditimbang untuk dihitung rendemennya. Ekstrak yang diperoleh adalah 498,825 g dan dari perhitungan rendemen ekstrak adalah $12,19 \%$.

Bobot serbuk simplisia yang diekstraksi $=498,825 \mathrm{~g}$

Bobot ekstrak yang diperoleh setelah penguapan $=60,816 \mathrm{~g}$

Rendemen esktrak $=\frac{\text { Bobot ekstrak }}{\text { Bobot simplisia }} \times 100 \%=\frac{60,816 \mathrm{~g}}{498,825 \mathrm{~g}} \times 100$

\section{Pembuatan Sediaan}

Sediaan emulgel dibuat dengan mencampurkan emulsi ke dalam basis gel. Sediaan emulgel dibuat dengan 3 variasi konsentrasi yaitu 10\%, 12\%, dan $15 \%$ ekstrak etanol daun jambu mete. Pada penelitian ini emulsi dibuat dengan pencampuran fase minyak dan fase air. Fase minyak yang digunakan terdiri dari minyak zaitun, Span 20 dan ekstrak etanol daun jambu mete. Selain sebagai fase minyak, minyak zaitun juga berfungsi sebagai emolien (Reynolds, 1982). Ekstrak etanol daun jambu mete dimasukkan ke dalam fase minyak. Pada fase minyak ditambahkan BHT sebagai antioksidan. Penambahan BHT di dalam sediaan bertujuan untuk mencegah proses oksidasi fase minyak. Fase air merupakan campuran antara air suling dan tween 60 . Masing-masing fase dipanaskan pada suhu $70^{\circ} \mathrm{C}$. Pencampuran dilakukan pada suhu $70^{\circ} \mathrm{C}$ sebab hampir semua bahan memiliki titik lebur pada suhu tersebut.
Dalam formula terdapat tween 60 dan span 20 yang merupakan bahan pengemulsi. Bahan tambahan lainnya adalah mentol yang digunakan sebagai pengharum untuk menutupi bau cabai dan pemberi sensasi sejuk ketika sediaan dioleskan ke kulit, propilen glikol sebagai humektan, dan etanol 96\% digunakan sebagai pelarut mentol serta untuk meningkatkan absorpsi perkutan dari sediaan topikal.

Basis gel karbomer memiliki $\mathrm{pH}$ asam. Oleh karena itu diperlukan adanya penambahan basa, seperti $\mathrm{NaOH}$ untuk meningkatkan $\mathrm{pH}$ basis sehingga $\mathrm{pH}$ menjadi lebih netral. Untuk membuat emulgel, emulsi yang telah dibuat dicampurkan ke dalam basis gel sedikit demi sedikit kemudian diaduk menggunakan homogenizer dengan kecepatan pengadukan $3000 \mathrm{rpm}$ selama 30 menit atau hingga terbentuk massa emulgel yang homogen. Perbandingan antara emulsi dan basis gel yang dicampurkan adalah 6:4. Perbandingan tersebut diperoleh dari hasil orientasi sebelumnya. Pada sediaan gel, ekstrak etanol daun jambu mete (Anacardium occidentale) langsung dicampurkan di dalam basis gel yang telah dibuat. Penggunaan mentol, propilenglikol, dan etanol 96\% memiliki fungsi yang sama seperti pada sediaan emulgel.

\section{Evaluasi Sediaan}

Masing-masing sediaan kemudian dievaluasi segera setelah selesai dibuat. Evaluasi sediaan pada minggu ke-o bertujuan untuk membandingkan keadaan masing-masing sediaan sebelum dan sesudah dilakukan uji kestabilan dengan parameter-parameter fisik sehingga dapat diketahui stabilitas sediaan selama penyimpanan. 


\section{Pengamatan Organoleptis}

Sediaan emulgel yang dihasilkan memiliki aroma mentol sehingga bau ekstrak etanol daun jambu mete (Anacardium occidentale)dapat tertutupi. Warna sediaan emulgel adalah hijau. Penampilan fisik sediaan emulgel pada minggu ke-o dapat dilihat pada Gambar 4 . Warna sediaan yang dihasilkan dipengaruhi oleh cara pencampuran ekstrak etanol daun jambu ke dalam sediaan. Ekstrak etanol daun jambu mete sendiri memiliki warna hijau kegelapan. Warna sediaan emulgel lebih muda sebab pada sediaan emulgel ekstrak etanol daun jambu mete dimasukkan ke dalam proses emulsifikasi dan terdispersi di dalam globul-globul minyak bersama fase minyak lainnya sehingga penambahan emulsi ke dalam basis gel membuat warna sediaan semakin muda. Warna sediaan semakin gelap berdasarkan semakin besar konsentrasi ekstrak daun jambu mete.

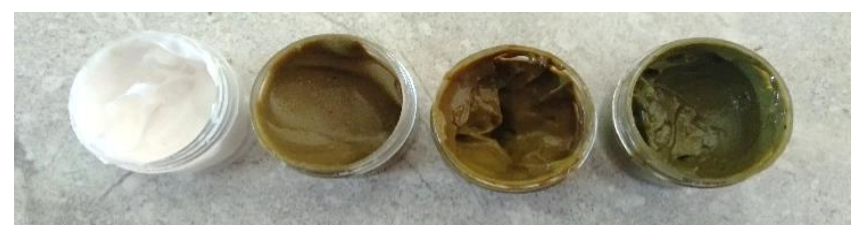

Gambar 1. Penampilan fisik sediaan. 1) emulgel tanpa ekstrak, 2) emulgel dengan ekstrak 10\%, 3)emulgel dengan Ekstrak 12\%, 4)emulgel dengan ekstrak 15\% (berturut-turut dari kiri ke kanan)

Tabel 2. Hasil uji organoleptik sediaan berdasarkan bentuk,bau dan warna sediaan.

\begin{tabular}{|c|c|c|c|c|c|}
\hline \multirow{2}{*}{ JENIS PEMERIKSAAN } & \multirow{2}{*}{ FORMULA } & \multicolumn{4}{|c|}{ MINGGU } \\
\cline { 2 - 6 } & & I & II & III & IV \\
\hline \multirow{3}{*}{ BENTUK } & $\mathrm{A}$ & Semi padat & Semi padat & Semi padat & Semi padat \\
\cline { 2 - 6 } & $\mathrm{B}$ & Semi padat & Semi padat & Semi padat & Semi padat \\
\cline { 2 - 6 } & $\mathrm{C}$ & Semi padat & Semi padat & Semi padat & Semi padat \\
\hline \multirow{3}{*}{ WARNA } & $\mathrm{A}$ & Hijau & Hijau & Hijau & Hijau \\
\cline { 2 - 6 } & $\mathrm{B}$ & Hijau & Hijau & Hijau & Hijau \\
\cline { 2 - 6 } & $\mathrm{C}$ & $\begin{array}{c}\text { Hijau } \\
\text { kehitaman }\end{array}$ & Hijau kehitaman & $\begin{array}{c}\text { Hijau } \\
\text { kehitaman }\end{array}$ & $\begin{array}{c}\text { Hijau } \\
\text { kehitaman }\end{array}$ \\
\hline \multirow{3}{*}{ BAU } & A & bau khas & bau khas & bau khas & bau khas \\
\cline { 2 - 6 } & B & bau khas & bau khas & bau khas & bau khas \\
\cline { 2 - 6 } & C & bau khas & bau khas & bau khas & bau khas \\
\hline
\end{tabular}

Ket : A = ekstrak daun jambu mete $5 \%$

$\mathrm{B}=$ ekstrak daun jambu mete $10 \%$

$\mathrm{C}=$ ekstrak daun jambu mete $15 \%$

\section{a) Homogenitas Sediaan}

Sediaan emulgel dengan ketiga konsentrasi ekstrak daun jambu mete serta kontrol emulgel tanpa ekstrak tampak homogen setelah dilihat menggunakan kaca objek. hal tersebut dapat dilihat dari tabel berikut:

Tabel. 3. Hasil uji homogenitas sediaan berdasarkan lama penyimpanan

\begin{tabular}{|c|c|c|c|c|}
\hline \multirow{2}{*}{ Formula } & \multicolumn{3}{|c|}{ Homogenoitas (Minggu ke) } \\
\cline { 2 - 5 } & I & II & III & IV \\
\hline A & Homogen & Homogen & Homogen & Homogen \\
\hline B & Homogen & Homogen & Homogen & Homogen \\
\hline C & Homogen & Homogen & Homogen & Homogen \\
\hline
\end{tabular}

Ket : A = ekstrak daun jambu mete $5 \%$

$\mathrm{B}=$ ekstrak daun jambu mete $10 \%$

$\mathrm{C}=$ ekstrak daun jambu mete $15 \%$ 


\section{b) Pengukuran pH}

Sediaan yang dihasilkan harus memiliki $\mathrm{pH}$ yang sesuai dengan $\mathrm{pH}$ kulit. Nilai pH sediaan emulgel pada minggu keo berturut-turut adalah 5,85 yang masih berada dalam rentang $\mathrm{pH}$ kulit, yaitu 4,5 dan 6,5 .

Tabel 4. Hasil uji pH sediaan berdasarkan lama penyimpanan

\begin{tabular}{|c|c|c|c|c|}
\hline \multirow{2}{*}{ FORMULA } & \multicolumn{4}{|c|}{ MINGGU } \\
\cline { 2 - 5 } & I & II & III & IV \\
\hline A & 5,85 & 5,85 & 5,85 & 5,85 \\
\hline B & 5,85 & 5,85 & 5,85 & 5,85 \\
\hline C & 5,85 & 5,85 & 5,85 & 5,85 \\
\hline
\end{tabular}

Ket : $\mathrm{A}=$ ekstrak daun jambu mete $5 \%$

$\mathrm{B}=$ ekstrak daun jambu mete $10 \%$

$\mathrm{C}=$ ekstrak daun jambu mete $15 \%$

\section{c) Pengukuran Viskositas dan Sifat} Alir

Untuk mengukur viskositas sediaan emulgel digunakan viscometer Brookfield. Pengukuran viskositas dilakukan pada spindel 6 dengan kecepatan putaran 20 rpm. Dari pengukuran dihasilkan nilai viskositas sediaan emulgel adalah 16500 cps. Sediaan emulgel memiliki viskositas yang lebih rendah daripada gel sebab di dalam emulgel terdapat komponen tambahan yang tidak ditambahkan pada sediaan gel. Komponen-komponen tersebut misalnya minyak zaitun dan bahan-bahan pengemulsi seperti tween 60 dan span 20 yang yang menyebabkan struktur 3 dimensi emulgel lebih renggang daripada gel. Hasil pengujian Daya lekat terhadap sediaan gel ekstrak daun jambu mete berdasarkan lama penyimpanan dapat dilihat pada tabel berikut:

Tabel. 5. Hasil uji viskositas sediaan berdasarkan lama penyimpanan

\begin{tabular}{|c|c|c|c|c|}
\hline \multirow{2}{*}{ FORMULA } & \multicolumn{4}{|c|}{ MINGGU } \\
\cline { 2 - 5 } & I & II & III & IV \\
\hline A & 126,66 & 140 & 126,66 & 136,66 \\
\hline B & 133,33 & 160 & 153,33 & 153,33 \\
\hline C & 183,33 & 196,66 & 183,33 & 183,33 \\
\hline
\end{tabular}

\section{KESIMPULAN}

Berdasarkan penelitian ini dapat disimpulkan bahwa ekstrak daun jambu mete (Anacardium occidentale L.) dapat diformulasi menjadi emulgel dengan karakteristik fisik yang baik sebagai emulgel. Karakteristik fisik tersebut berdasarkan pemeriksaan organoleptik, homogenitas, konsistensi, $\mathrm{pH}$, penentuan viskositas, uji daya sebar, uji extrudability dan uji swelling index. Emulgel ekstrak daun jambu mete dapat dibuat dengan menggunakan basis karbomer. Formula I, VI, VII dan IX merupakan formula yang mempunyai karakteristik paling baik sediaan emulgel ekstrak daun jambu mete (Anacardium occidentale L.).

\section{UCAPAN TERIMA KASIH}

Penulis menyampaikan banyak terimakasih kepada Yayasan Mandala WaluyamelaluiStikes Mandala Waluya Kendari yang telah memberikan dana untuk penelitian ini. Ucapan terimakasih juga disampaikan kepada Kepala Program Studi Farmasi dan Kepala Laboratorium atas ijin dan fasilitas penggunaan laboratorium selama penelitian. 
DAFTAR PUSTAKA

ASEAN. (1993). Standard of ASEAN Herbal Medicine (Vol.1). Jakarta: ASEAN Countries, 89-103.

Bhanu, P. V., Shanmugam, V., dan Lakshmi, P. K. (2011). Antimicrobial Preservative Activity of The formulated Diclofenac Emulgel, A Novel Drug Delivery for Topical Use. The Pharma Professionals, 1 (1), 510.

Bhanu, P. V., Shanmugam, V., dan Lakshmi, P. K. (2011). Development and Optimization of Novel Diclofenac Emulgel for Topical Drug Delivery. Pharmace Globale (IJCP), 9 (10), 1-4.

Bradley, P. (2006). British Herbal Compendium (Vol.2). Bournemourth: British Herbal Medicine Association, 83-88.

Catz, P. dan Friend, D. (1990). Transdermal Delivery of Levonorgestrel VIII. Effect of Enhancers on Rat Skin, Hairless Mouse Skin, Hairless Guinea Pig Skin, and Human Skin. International Journal Pharmaceutics, 5893, 102.

Departemen Kesehatan Republik Indonesia. (2000). Parameter Standar Umum ekstrak Tumbuhan Obat. Jakarta: Departemen Kesehtan Republik Indonesia, 3-12.

Dewick, P. M. (2009). Medicinal Natural Products: A Biosynthetic Approach (3rd Ed.). Wiltshire: John dan Wiley, 405.

DiPiro, J.T., Talbert, R. L., Yee, G. C., Matzke, G. R.., Wells, B. G., dan Posey, L. M. (2005). Pharmacotherapy:

Pathophysiologic Approach, (6th Ed.) USA: The McGraw-Hill Companies, 1337-1340.

Djajadisastra, J. (November, 2004). Cosmetic Stability. Disampaikan pada "Seminar Setengah Hari HIKI". Slipi, Jakarta.
Dragicevic-Curic, N., Winter, S., Stupar, M., Milic, J., Krajišnik, D., Gitter, B., dan Fahr, A. (2009). Temoporfinloaded Liposomal Gels: Viscoelastic Properties and In Vitro Skin Penetration. International Journal of Pharmaceutics, 373, 77-84.

Iswandana, Raditya. (2009). Penetapan Daya Penetrasi Secara In Vitro dan Uji Stabilitas Fisik Sediaan Krim, Salep, dan Gel yang Mengandung Kurkumin dari Kunyit (Curcuma longa L.). Skripsi Sarjana Farmasi. Depok: FMIPA UI, 35-37.

Jain, A., Gautam, S. P., Gupta, Y., Khambete, H., dan Jain, S. (2010). Development and Characterization of Ketoconazole Emulgel for Topical Drug Delivery. Dermatological Pharmacia Sinica, 1 (3), 221-231.

Jain, A., Deveda, P., Vyas, N., Chauhan, J., Khambete, H., dan Jain, S. (2011). Development of Antifungal Emulsions Based Gel for Topical Fungal Infection(s). International Journal of Pharmaceutical Research and Development (IJPRD), 2 (12), 18-25.

Jia-You Fang, Ying-Yue Wang, Chi-Tzong Hong, dan Wen-Ta Chiu. (2001). In Vitro and In Vivo Evaluations of Topically Applied Capsaicin and Nonivamide from Hydrogels. International Journal of Pharmaceutics (224), 89104.Kumar, L., dan Verma. (2010). In Vitro Evaluation of topical Gel Prepared Using Natural Polymer. International Journal of Drug Delivery, 2, 58-63. 